\title{
INTEgRATED CARE A message from HRH The Prince of Wales, honorary fellow of the Royal College of Physicians
}

\author{
Author: HRH The Prince of Wales
}

KEYWORDS: inequality, integrated healthcare, social prescription

DOI: $10.7861 /$ fhj.8.1.hrh

\section{Introduction}

The COVID-19 pandemic has focused people's minds on healthcare as never before. No-one who has witnessed the events of the past year could fail to be profoundly impressed with the dedication and selfless commitment of all in our NHS.

Researchers have devised pioneering vaccines and treatments under conditions of the most pressing urgency. Public authorities have responded with patient persistence to an ever-mutating threat. Volunteers have given their time and their talents to assist those less fortunate than themselves. Communities have shown their willingness to make costly sacrifices to help society tackle its greatest-ever peacetime crisis. And the importance of taking regular exercise has been specifically built into government guidelines.

\section{An integrated approach}

This whole experience has shown the transformative effect on health outcomes that can be achieved with an integrated approach combining science, public policy and personal behaviour. In this case, it has been the necessary response to a sudden acute threat. I have long wished for a similarly integrated approach to the more chronic health issues our society experiences.

For as long as I care to remember, I have suggested that medicine should become more integrated and inclusive. Integration is not simply about how we bring together different perspectives and traditions in diagnosis and treatment. Nor is it about rejecting conventional medicines in favour of other treatments: the term 'complementary' medicine means precisely what it says. I believe we must also integrate the treatment of disease with the prevention of disease, and the subsequent improvement in people's lifestyles, genuinely to promote national health and not just remediate national illness. Whatever we do to improve the health of an individual should be matched with our attempts to improve the health of whole communities and, on a larger scale still, we should aim for a better balance between shortterm economics and the long-term good of the planet.

Food provides a good example of integration in the sense that I mean. In hospitals, and often in the community, we concentrate on the health benefit of medicines, but it seems that the health benefit of food is often an afterthought when it comes to treatment or medical training. Yet we know that food is the one of the determining factors in maintaining good health and wellbeing, and avoiding disease. ${ }^{1,2}$ Therefore, is it not logical that food and diet should be a part of many, if not most, medical consultations? While an increasing number of people are seeking to buy, and eat, seasonable food of good provenance that is unadulterated by chemicals and pesticides, this is sadly not so for many who may not be able to afford or may not want to eat a healthier diet. This is partly a factor of the lack of true cost accounting and perverse economic forces that encourage our farmers, producers and retailers to offer less healthy food because it is cheaper. This ignores the social and environmental costs as well as the resulting costs to the health service. In environmental terms, this leads to unsustainable farming practices which provide short-term profit, but which deplete the soil of its rich microbiome just as unhealthy food depletes our own internal human microbiomes. ${ }^{3,4}$

Adopting a whole-community and system approach to the promotion of affordable healthy eating seems to me the logical next step and fits well with the new advances I have been hearing about in the science of personalised lifestyle medicine. ${ }^{5,6}$ Because if we are going to focus our efforts to improve health effectively, then in future, we must take into account not only genetics but also other factors such as our individual metabolisms, our environmental exposure and even our gut biomes. Only then can we begin to understand properly why factors such as obesity and our eating habits can have such a huge effect on each individual's ability to withstand infection and pollution.

Of course, these issues of caring better about our food, the soil, animals, fish and the environment also have far wider implications. They affect our physical and mental resilience generally, our ability to withstand epidemics and natural disasters and are directly relevant, of course, to the issue of climate change itself.

Without an integrated approach of this kind, I cannot see how we can ever tackle these problems. I am not saying that medicine needs to join debates on sustainable farming and financial penalties and subsidies, but it seems to me that doctors have a crucial role in affirming the importance of good quality food just as they do good quality medicines.

\section{Social prescription}

For a long time, I have been an advocate of what is now called social prescription and this may just be the key to integrating the biomedical, the psychosocial and the environmental, as well as 
the nature of the communities within which we live and which have such an enormous impact on our health and wellbeing. ${ }^{7}$ In particular, I believe that social prescription can bring together the aims of the health service, local authorities, and the voluntary and volunteer sector. Biomedicine has been spectacularly successful in treating and often curing disease that was previously incurable. Yet it cannot hold all the answers, as witnessed, for instance, by the increasing incidence of long-term disease, antibiotic resistance and opiate dependence. Social prescription enables medicine to go beyond pills and procedures and to recognise the enormous health impact of the lives we lead and the physical and social environment within which we live. This is precisely why I have spent so many years trying to demonstrate the vitally important psychosocial, environmental and financial added value of genuinely, sustainable urban planning, design and construction.

There is research from University College London, for instance, which shows that you are almost three times more likely to overcome depression if you have a hobby. ${ }^{8}$ Social prescription enables doctors to provide their patients with a bespoke prescription that might help them at a time of need (such as advice on housing and benefits) but which may also provide them with opportunities, hope and meaning by being able to engage in a range of physical, environmental and artistic activities, which resonate with where they are in their lives. Furthermore, social prescription has the potential not only to transform our understanding of what medicine is and does, but also to change the communities in which we all live. I understand, for instance, that alongside social-prescription link workers, there are now people responsible for redesigning and increasing the capacity of the local volunteer and voluntary sector, who can help to create a new social infrastructure and eventually, one might hope, communities that make us healthier rather than making us ill.

When we hear that a quarter of 14-16-year-old girls are self-harming and almost a third of our children are overweight or obese, it should make us realise that we will have to be a bit more radical in addressing these problems. ${ }^{9,10}$ And though social prescription cannot do everything, I believe that, used imaginatively, it can begin to tackle these deep-rooted issues. As medicine starts to grapple with these wider determinants of health, I also believe that medicine will need to combine bioscience with personal beliefs, hopes, aspirations and choices.

Many patients choose to see complementary practitioners for interventions such as manipulation, acupuncture and massage. Surely in an era of personalised medicine, we need to be openminded about the choices that patients make and embrace them where they clearly improve their ability to care for themselves? Current NHS guidelines on pain that acknowledge the role of acupuncture and mindfulness may lead, I hope, to a more fruitful discussion on the role of complementary medicine in a modern health service. ${ }^{11}$ I have always advocated 'the best of both worlds', bringing evidence-informed conventional and complementary medicine together and avoiding that gulf between them, which leads, I understand, to a substantial proportion of patients feeling that they cannot discuss complementary medicine with their doctors. 12,13

I believe it is more important than ever that we should aim for this middle ground. Only then can we escape divisions and intolerance on both sides of the conventional/complementary equation where, on the one hand, the appropriate regulation of the proven therapies of acupuncture and medical herbalism is opposed while, on the other, we find people actually opposing lifesaving vaccinations. Who would have thought, for instance, that in the 21st century that there would be a significant lobby opposing vaccination, given its track record in eradicating so many terrible diseases and its current potential to protect and liberate some of the most vulnerable in our society from coronavirus?

\section{Conclusion}

I believe that future medicine will need to go beyond integrating treatment for the individual patient, whether it be a conventional, complementary or lifestyle approach. It will need to connect fully with local communities and become more relevant to the health of the local population by applying a systems approach in all healthrelated areas, from social inequalities to climate change and the planning and design of the built environment which enhances community through mixed-income, mixed-use development. Of course, that presents enormous challenges for the medical profession, but doctors' opinions have always been taken seriously. This is why I believe it is so important that the medical community rises to these challenges and takes on an extended role in enabling healthier and happier communities in a more joined-up world, in which we are all individually and collectively enabled to live healthier lives.

\section{References}

1 The health Foundation. Our food and our health: How is our health influenced by the food we eat? The Health Foundation, 2017. www.health.org.uk/infographic/our-food-and-our-health

2 Yau A, Adams J, White M. Is food security associated with diet and health? A cross-sectional online panel of adults in the UK. Lancet 2018;392:S96.

3 McMichael AJ, Powles JW, Butler CD, Uauy R. Food, livestock production, energy, climate change, and health. Lancet 2007;370:1253-63.

4 Amundson R, Berhe AA, W. Hopmans JW et al. Soil and human security in the 21st century. Science 2015;348:1261071. https:// science.sciencemag.org/content/348/6235/1261071?ijkey $=\mathrm{db}$ c1946e96bbc8a36019ae7ade03ab18d7e5be3d\&\#38;keytype 2=tf_ipsecsha

5 NHS. Personalised medicine. NHS. www.england.nhs.uk/healthcarescience/personalisedmedicine

6 Ornish D. We should remember that simple lifestyle changes can be as effective as advances in medicine. College of Medicine and Integrated Health, 2020. https://collegeofmedicine.org.uk/deanornish-we-should-remember-that-simple-lifestyle-changes-can-beas-effective-as-advances-in-medicine

7 College of Medicine and Integrated Health. Social prescribing. College of Medicine and Integrated Health. https:// collegeofmedicine.org.uk/social-prescribing

8 Fancourt D, Opher S, de Oliveira C. Fixed-effects analyses of timevarying associations between hobbies and depression in a longitudinal cohort study: support for social prescribing? Psychother Psychosom 2020;89:111-3.

9 Marsh S, Boateng A. Quarter of 14-year-old girls in UK have selfharmed, report finds. Guardian 2018. 
10 NHS Digital. Health survey for England 2018 [NS]. NHS, 2019.

11 National Institute for Health and Care Excellence. Headaches in over 12s: diagnosis and management: Clinical guideline [CG150] NICE, 2015. www.nice.org.uk/guidance/cg150

12 Sanford NN, Sher DJ, Ahn C, Aizer AA, Mahal BA. Prevalence and nondisclosure of complementary and alternative medicine use in patients with cancer and cancer survivors in the United States. JAMA Oncol 2019;5:735-7.
13 Shelley BM, Sussman AL, Williams RL, Segal AR, Crabtree BF. 'They don't ask me so i don't tell them': Patient-clinician communication about traditional, complementary, and alternative medicine. Ann Fam Med 2009;7:139-47.

Address for correspondence: Clarence House, London SW1A 1BA, UK. 

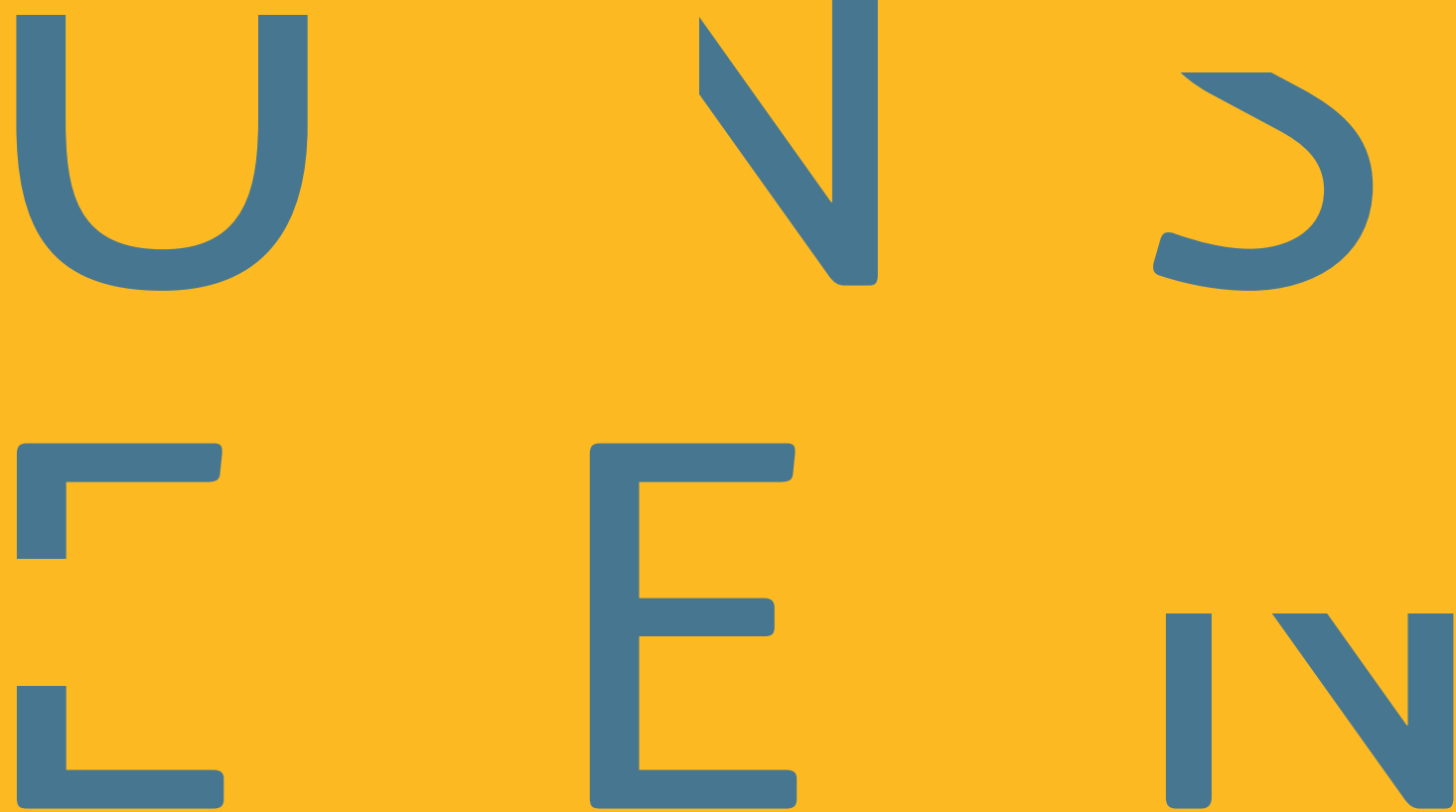

\section{RCP Unseen open online during 2021}

The history of medicine like you've never seen it before.
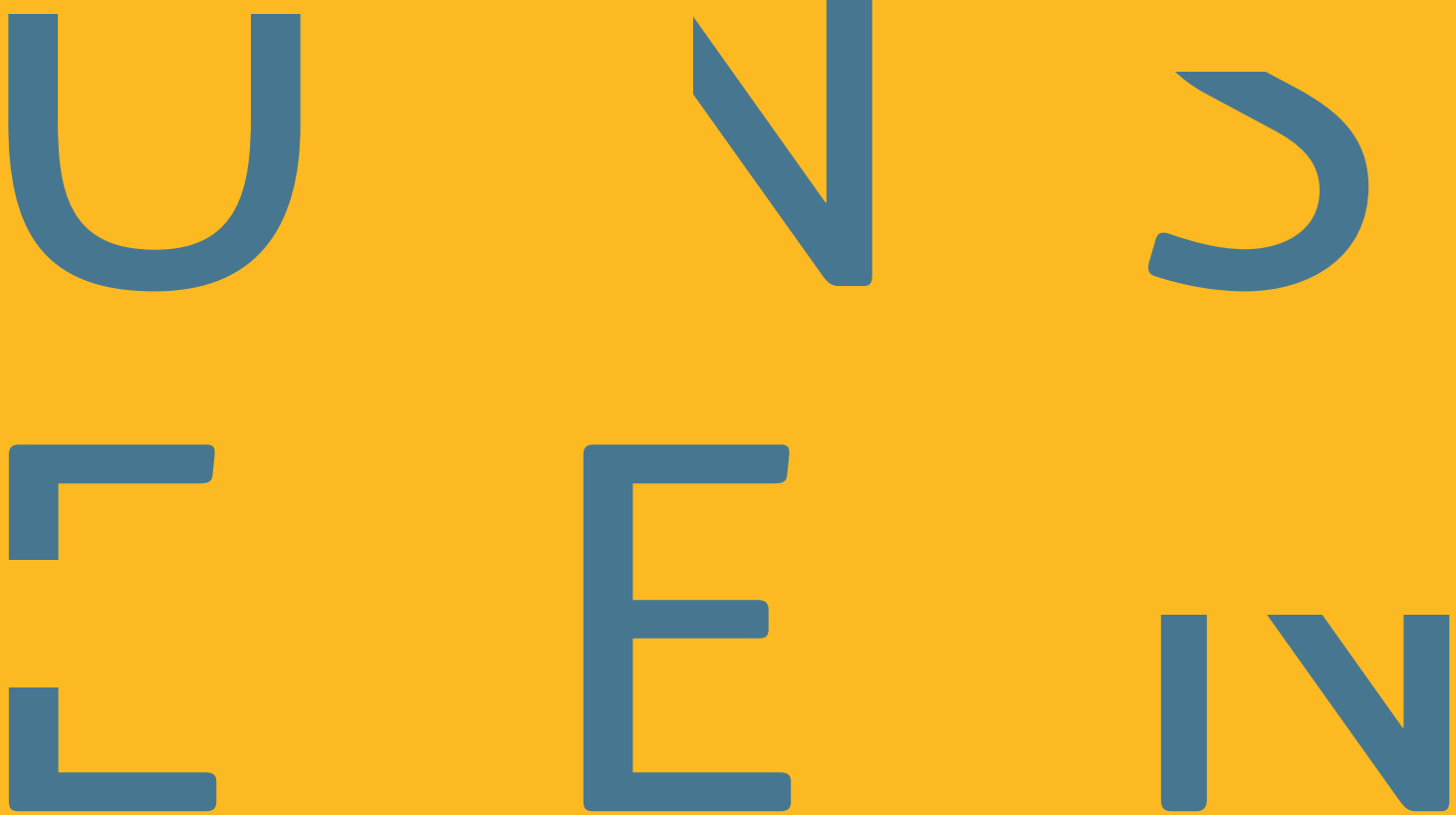
of Physicians

history.rcplondon.ac.uk /exhibitions/rcp-unseen f $\because 00$ @RCPmuseum \#RCPunseen 